\title{
SISTEMATIZAÇÃO DE DADOS: UMA ANÁLISE DO ESTADO DA ARTE NO CAMPO EDUCACIONAL
}

\author{
http://dx.doi.org/10.5902/2318133836283
}

\author{
Assis Leão da Silva ${ }^{1}$ \\ Vilma de Albuquerque Santos ${ }^{2}$ \\ Cristiano Dornelas de Andrade ${ }^{3}$ \\ Wilma dos Santos Ferreira ${ }^{4}$
}

\begin{abstract}
Resumo
Neste texto se analisa a produção acadêmica a respeito de mecanismos de informação doravante monitoramento - no campo educacional, identificando e descrevendo nas pesquisas a temática da sistematização de dados para gestão educacional. Como procedimento metodológico utilizou-se a pesquisa bibliográfica do tipo sistemática. Os dados foram obtidos pelo portal de periódicos da Capes, base de dados do Scielo e Scielo Educ@. Busca-se ampliar a complexa posição conceitual da pesquisa ao qual está vinculado, revisitando a literatura existente, delineando o estado da arte, para reconhecer as diferentes contribuições científicas sobre a temática problematizada. Consta-se que a sistematização de dados é uma temática a ser explorada no campo educacional.

Palavras-chave: monitoramento; gestão educacional; estado da arte.
\end{abstract}

\section{SYSTEMATIZATION OF DATA: AN ANALYSIS OF THE STATE OF ART IN THE EDUCATIONAL FIELD}

\section{Abstract}

The paper analyzes the academic production regarding information mechanisms - henceforth monitoring - in the educational field, identifying and describing in the research the thematic of data systematization to educational management. As a methodological procedure we used bibliographical research of the systematic type. It presents as reference the Capes journal portal, the Scielo and Educ@ database. Also, it seeks to broaden the complex conceptual position of the research to which it is linked, revisiting the existing literature, outlining the state of the art, to recognize the different scientific contributions on the subject matter. The systematization of data, henceforth monitoring, is a subject to be explored in the educational field.

Key-words: monitoring; educational management; state of art.

\footnotetext{
${ }^{1}$ Instituto Federal de Educação, Ciência e Tecnologia de Pernambuco, Brasil. E-mail: assisleao33@gmail.com.

2 Universidade Federal de Pernambuco, Brasil. E-mail: vilmaalbuquerque19@gmail.com.

3 Universidade Federal de Pernambuco, Brasil. E-mail: cristianodornelas@hotmail.com.

4 Universidade Federal de Pernambuco, Brasil. E-mail: wilmadsferreira@gmail.com.

Regae: Rev. Gest. Aval. Educ. Santa Maria

v. 8

n. $17 \quad$ Pub. contínua 2019

p. $1-24$
} 


\section{Introdução}

1 s políticas públicas alcançaram transformações gradativas e cumulativas no âmbito social e educacional nas últimas décadas, concomitantemente, romperam com a ideologia do Estado idealizador e os sujeitos como executores desta ação reflexiva (Gomes, 2011). Não obstante, historicamente no Brasil, esta agenda consolidou e articulou-se ao modelo de desenvolvimento da sociedade.

Segundo Trevisan e Bellen (2008), entre os anos de 1960 e 1970 a agenda das políticas públicas influenciadas pelo campo da economia voltaram-se aos efeitos redistributivos da ação estatal associada à racionalidade promotora de uma modernização conservadora. Posteriormente, nos anos de 1980, com a transição para o regime democrático, ocorreram mudanças substantivas nesta tendência conservadora.

Diferentemente do período anterior, o desenvolvimento das políticas sociais articulou-se às novas questões-chave em torno de uma agenda das políticas públicas, agora, amparada nos princípios da transparência, da participação e da ressignificação das relações entre o público e o privado. Esse novo momento impôs ao Estado brasileiro novos desafios em torno da efetividade das políticas sociais.

Nos anos de 1990, esta agenda continuou a desenvolver-se com os princípios da década anterior, porém articulando-se ao ideário de reforma do Estado e do seu aparelho amplamente difundido no contexto internacional. É, neste contexto, no cenário nacional que ocorreu a difusão de inúmeros estudos sobre políticas públicas problematizando 0 modus operandi e a qualidade da ação estatal no campo social.

A análise do Estado em ação (Azevedo, 2004) passa a adquirir visibilidade ao problematizar-se a sua efetividade, por meio do estudo da implementação das políticas e programas sociais (Belloni; Magalhães; Sousa, 2007). No campo educacional, a partir dos anos de 1990, com a reforma do Estado e, consequentemente, da educação, a problematização e o panejamento de estratégias de garantia desta efetividade adquiriu visibilidade (Cohen; Franco, 2008).

Dentre as diversas práticas institucionais que compõem as políticas públicas no campo educacional, encontra-se a avaliação, como parte de um sistema que se justifica, no discurso oficial da regulação, de controle ao qual se acredita que se pode promover a nível macro. Partindo-se dos dispositivos da Lei de Diretrizes e Bases da Educação Nacional LDB/1996, é do Estado a obrigação em avaliar o sistema de Educação Superior e Educação Básica em sua globalidade. Sobre esta lógica da regulação que a avaliação adquiriu centralidade, não só como fator inerente ao ensino, mas, também como forma da gestão educacional dispor de parâmetros de qualidade às políticas educacionais.

Tais perspetivas postularam a avaliação como um instrumento imprescindível para a gestão e para as ações públicas, pois as práticas avaliativas são evidenciadas em situações, realidades e contextos específicos que norteiam ações diretas e objetivas em prol de ajustes contextuais.

Entretanto, nos últimos anos, os casos de formulação e implementação de políticas

de avaliação no âmbito da educação constituiu-se numa das evidências mais emblemáticas deste fenômeno, sobretudo, quando associada à agenda democrática impondo desafios relevantes em torno de dívidas históricas referentes aos diversos grupos da sociedade posicionados à margem do campo educacional no tocante ao acesso, permanência e êxito. 
Por esta razão, a sociedade em seu conjunto está cada vez mais exigente quanto à sua relevância e ciente de suas repercussões no tocante à necessidade de alcançar melhores perspectivas de efetividade no campo educacional. Esse aspecto indica o cenário de mudança na maneira como a sociedade visualiza a implementação e pleiteia suas expectativas em torno das políticas de avaliação.

Neste contexto das políticas educacionais, em especial das políticas de avaliação, as instituições educacionais caracterizam-se pela pluralidade de interesses, valores, crenças e compromissos. A gestão das instituições educacionais dar-se mediante uma tradição de organização institucional historicamente construída através do consenso e tensões, entraves e possibilidades, entre os diversos setores envolvidos no processo educacional - governos, famílias, mercado, sociedade civil, gestores, professores, técnicos administrativos, alunos.

No entanto, esse tensionamento não promoveu o êxito esperado, como aconteceu em outras regiões do mundo, ao possibilitar o desenvolvimento e consolidação da teorização de dois campos do conhecimento, o campo da avaliação educacional e o campo da avaliação de políticas públicas, ambos com o mesmo objeto de estudo, a educação, e interdependentes. Porém, com abordagens distintas e ao mesmo tempo complementares, sob a hegemonia dos interesses do Estado em ampliar a governança nos sistemas educacionais.

Observando esta lacuna em ambas as áreas no cenário nacional, sobretudo, voltado aos diagnósticos da avaliação educacional e da avaliação de políticas públicas, este trabalho aponta para uma das possibilidades clássicas reconhecidas e recomendadas pela literatura acadêmica internacional - Stake, 1967; Parlett; Hamilton, 1972) para conduzir os múltiplos fluxos de interesses a respeito do desenvolvimento das organizações e gestão das instituições educacionais, a construção/consolidação de mecanismos de informação sobre as ações institucionais, denominado no contexto social nacional de monitoramento.

Para esses autores, em contraponto a uma visão da tradição racionalista da avaliação (Guba; Lincon, 2011), a construção desses mecanismos de informação em ambos os campos do conhecimento visa, inicialmente, possibilitar o acesso e a publicidade dos dados, desvelando as complexidades políticas em torno das tomadas de decisões ao dirigir e compartilhar informações entre grupos diferentes com interesses distintos em relação ao objeto educacional. Em segundo lugar, possibilitar juízos de valor a respeito da consecução e questionamento dos objetivos propostos e estabelecidos, no caso, a eficácia nos documentos oficiais e na legislação educacional.

House (1973), já na década de 1970, observando os diversos usos da avaliação, em especial para o modelo de regulação do sistema educacional, alertava que estas sistematizações de informações não deveriam se restringir a uma prestação de contas, denominada por ele de mecanicista, caracterizada por uma ética e poder utilitarista (House, 2000) baseada na produtividade: conhecimento das causas e efeitos, para menção de controle desprezando os contextos históricos e sociais. 
Mas, assumir a condição de fomento à profissionalização dos atores, em seus contextos de atuação, diretamente envolvidos no processo educacional, gestores, professores e técnicos administrativos. Apropriando-se de Silva (2015), estas informações devem possibilitar o diálogo e uma tomada de decisões compartilhadas e coletivas, qualificando e legitimando as ações institucionais no contexto das políticas de avaliação.

Essa preocupação deve-se ao fato de que nos sistemas educacionais, numa abordagem clássica, como apontam Dupriez e Maroy (2000) o modelo analítico de pilotagem dos sistemas educativos elaborada por De Landheere (1997) associa-se à abordagem institucional hierarquizada, constituindo-se e caracterizando-se pela racionalização voltada para consecução dos objetivos. Na visão de De Landheere (1997) a pilotagem pode ser visualizada em processos de regulação promovidos pelas avaliações.

Este último autor esboça três tipos de pilotagem no sistema educacional: pilotagem administrativa ou monitoramento de conformidade; pilotagem formativa ou diagnóstica e a pilotagem do rendimento escolar. A primeira volta-se para verificação dos regulamentos estabelecidos a priori; a segunda, baseada nas avaliações estandardizadas, volta-se ao estabelecimento de metas; a terceira volta-se para a análise do sistema educacional, para rever as políticas e supervisionar os professores, além de orientar as instituições educacionais. É neste cenário que a sistematização de informação, denominada de monitoramento ou mecanismos de informação se insere.

Dessa maneira, neste trabalho, subsidiado pelas contribuições de House (1973, 2000); Azevedo (2004); Belloni Magalhães e Sousa (2007) parte-se do pressuposto de que para o campo da avaliação educacional e da avaliação de políticas públicas no tocante ao objeto educação, não é interessante restringir a pilotagem no sistema educacional a apenas a pilotagem administrativa ou monitoramento de conformidade, amparada exclusivamente numa perspectiva paradigmática racionalista de causa e efeito.

Todavia, faz-se necessário ampliá-la, associando abordagem racionalista, quantitativo, e naturalista, qualitativo, no uso dos mecanismos de informação monitoramento - nas políticas educacionais e na avaliação educacional - buscando-se, então, a compreensão dos fenômenos estudados - a abordagem naturalista (Guba; Lincoln, 2011) - para articular e ressignificar o uso dos três sistemas de pilotagem descritos por De Landheere (1997) no contexto atual de regimes de regulação pósburocráticos.

Por essa razão, conhecer as diferentes contribuições científicas sobre a sistematização de dados ou mecanismos de informação - monitoramento - aplicados ao campo das políticas educacionais, em especial daquelas voltadas à avaliação, é o objetivo deste trabalho revisitando a literatura existente com o intuito de buscar ampliar essa complexa posição conceitual, delineando o estado da arte sobre a temática problematizada.

\section{Metodologia}

A pesquisa bibliográfica é muito adequada em situações referentes ao contato inicial do pesquisador com as fontes de coleta de dados, proporcionando "maior familiaridade com o problema, com vistas a torná-lo mais explícito ou a constituir hipóteses (Gil, 1999, 
p. 41). Por esta razão, este tipo de pesquisa possui planejamento flexível, permitindo o estudo do tema sobre diversas perspectivas e aspectos, caracterizando-se como um estudo exploratório-descritivo.

Enquanto estudo teórico realizado por meio da reflexão pessoal e da análise de documentos escritos, segue um ordenamento de procedimentos (Salvador, 1986). Entretanto, não significa que os procedimentos realizados foram determinados a priori, pois mesmo que tenha-se delimitado o objeto de estudo, poderia-se voltar ele à medida que fossem obtidos os dados, de modo a delimitá-lo mais nitidamente ou reestruturá-lo. Portanto, esse movimento implicou em novas alterações ou escolhas quanto aos procedimentos metodológicos da pesquisa..

Nesta lógica, a coleta de dados foi iniciada com o estabelecimento de parâmetros que demarcam o objeto de estudo, orientando a seleção do corpus documental. Isso exigia demarcação do parâmetro temático: as obras associadas ao objeto de estudo, de acordo com os temas que são similares; o parâmetro linguístico: obras no idioma português; as principais fontes que se pretendeu consultar: periódicos, teses e dissertações; o parâmetro cronológico de publicação: definição definindo do período a ser analisado.

A partir da seleção desses parâmetros determinou-se a técnica a ser utilizada para a investigação. Sendo assim, à pesquisa bibliográfica, a leitura destacou-se como o aspecto fundamental da técnica, pois foi por meio desta que se pode levantar as informações, bem como averiguar as relações existentes.

Ao abordar a pesquisa bibliográfica é relevante afirmar que ela é sempre realizada para fundamentar teoricamente o objeto de estudo, colaborando com elementos que auxiliam a análise futura dos dados coletados. Assim sendo, distingue-se da revisão bibliográfica, uma vez que vai além da simples observação de dados contidos nas fontes pesquisadas, pois imprime sobre eles a teoria, a compreensão crítica do significado neles existente. O debate acerca dos pressupostos teórico-conceituais norteadores do conhecimento dos modelos propostos na formulação e implementação de avaliação de políticas públicas, em especial nas áreas sociais, não é uma temática nova na literatura acadêmica nacional e internacional. O estudo exploratório foi desenvolvido consoante às proposições elaboradas por Marconi e Lakatos (2010) e Stake (2011).

Esta pesquisa foi composta dos seguintes procedimentos: a) escolha dos temas e subtemas; b) levantamento bibliográfico preliminar; c) formulação do problema; d) elaboração do plano provisório do assunto; e) busca de fontes; f) classificação; g) leitura do material; h) fichamento; i) organização lógica do assunto no banco de dados. Para a realização da pesquisa bibliográfica, foram planejadas duas frentes de trabalho relacionados à base do Scielo; Educ@e Portal de Periódicos da Capes. O objetivo deste trabalho consistiu em levantar elementos que subsidiassem na classificação dos artigos por áreas do conhecimento na categoria temática monitoramento nas áreas de Ciências Sociais e Ciências Humanas, associando aos campos da avaliação educacional e da avaliação de políticas públicas, com o intuito de verificar a incidência e o modus operandi do desenvolvimento de pesquisas e relatos de experiências relacionados às políticas de 
avaliação, que possam colocar os pesquisadores em contato direto com o que vem sendo publicado e oferecer meios para definir, resolver e explorar problemas que ainda não se cristalizaram suficientemente no desenvolvimento de mecanismos de informação, doravante monitoramento, no campo educacional.

\section{Resultados e discursões}

Nesta seção serão apresentados e discutidos os dados levantados e analisados na pesquisa realizada. Com o intuito de desenvolver esta tarefa de maneira mais clara possível, a seção foi subdividida em duas partes. $\mathrm{Na}$ primeira, apresenta-se o levantamento da produção científica nas bases de dados Scielo e Educ@, caracterizandose tendências e a perspectiva de produção científica a respeito da temática monitoramento. Na segunda parte analisa-se a tendência e perspectiva do perfil da produção científica sobre a categoria monitoramento no grupo temático das Ciências Humanas voltados ao campo educacional na base de dados Portal de Periódicos Capes.

Levantamento, tendências e perspectivas da produção científica sobre a categoria temática "monitoramento": mapeamento em grupos temáticos na base do Scieloe Educ@

No gráfico a seguir, observa-se o quantitativo por área temática dos documentos encontrados na base de dados da Scielo e Educ@.

Gráfico 1 -

Monitoramento: Área Temática na base de dados do Scielo e Educ@.

Monitoramento: Área Temática na base de dados do Scielo e Educ@

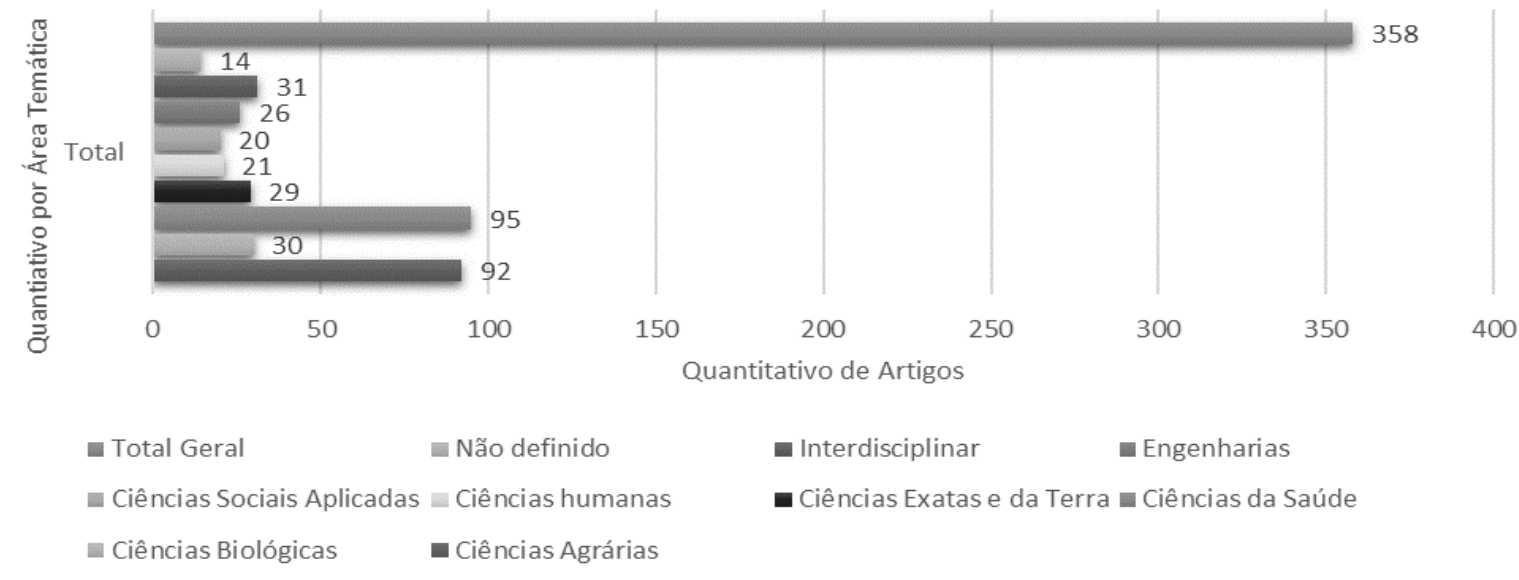

Fonte: Educ@ e Scielo.

Foram encontrados o total de 358 artigos, sendo subdivididos por áreas. Na área de Ciências Sociais Aplicadas foram encontrados vinte artigos, classificados pela palavra monitotamento; na área Ciências Biológicas, trinta artigos; na área de Ciencias Humanas 21 artigos; na área de Ciências Agrárias 92 artigos; nas áreas interdisciplinar 31 artigos; 
nas área Ciências Exatas e da Terra, 29 artigos; na área de Engenharias 26 artigos e na área de Ciências da Saúde 95 artigos. Entretanto, 14 artigos não foram classificados por ambas as base de dados em nenhuma área do conhecimento.

Nestas duas bases de dados a temática monitoramento é predominantemente uma discussão de duas áreas do conhecimento: Cências da Saúde e Ciências Agrárias. Mesmo nos trabalhos que apresentaram uma natureza interdisciplinar, estas duas áreas do conhecimento assumiram papel de destaque. As áreas de Ciêncas Humanas e Ciências Sociais, foco da pesquisa em questão, aparecem no levantamento de dados com menor incidência de trabalhos em relação às demais áreas do conhecimento, com 21 e vinte artigos, respectivamente.

Analisando para além e amparado no gráfico, diferentemente da área de Ciências Agrárias, a área de Ciências da Saúde desenvolveu as problematizações sobre monitoramento delimitando-a aos aspectos metodológicos do próprio campo e, em menor incidência, ao campo da avaliação de políticas públicas. Chamou a atenção a incidência de natureza interdisciplinar que a temática assumiu em ambas as bases de dados, especialmente, na base de dados Scielo, com um perfil mais ambrangente do que a Educ@, direcionada ao campo educacional.

A visibilidade destas duas áreas do conhecimento, no debate a respeito do monitoramento, podem oferecer evidências de influências nas áreas das Ciências Humanas e das Ciências Sociais nas preferências por determinadas abordagens e perspectivas paradigmáticas, em especial as abordagens racionalistas - positivista e póspositivista - de cunho funcionalista, caracterizadas pelo aspecto de causa e efeito, objetivada na esperança do controle, como nas áreas Ciências Naturais, no campo social, consequentemente, educacional (Guba; Lincoln, 2011).

Apropriando-se de Silva (2015), o gráfico possibilita inferir as primeiras aproximações quanto ao reconhecimento do sentido e sugerir o significado das concepções que o monitoramento pode vir a assumir em distintos contextos do campo científico, histórico e social, reportando-se à algumas das principais tendências da avaliação no âmbito da constituição do campo da avaliação educacional e da avaliação de políticas públicas para o contexto atual.

Possibilita identificar o sentido conferido à mensuração, objetivo e juízo de valor, elementos essenciais associados aos processos de monitoramento (Guba; Lincoln, 2011). No campo das Ciências Humanas e das Ciências Sociais esses elementos essenciais, influenciados pelos paradigmas das áreas das Ciências da Natureza, como as áreas de Ciências Agrária e da Saúde, impactam as

práticas avaliativas e políticas de avaliação, caracterizadas pelo gerencialismo, [onde] um dos problemas mais relevantes refere-se à proeminência dos parâmetros e delimitações estabelecidos pelas autoridades e administradores da avaliação (Silva, 2015, p. 79).

Então, desse modo o monitoramento, nas áreas das Ciências Humanas e das Ciências Sociais, assume a abordagem funcionalista, amparado no paradigma racionalista - positivismo e pós-positivismo - com o papel de analisar as suas mudanças, verificando os fatores que produzem desordem e dirigindo os rumos para conservação do equilíbrio. 
Entre as críticas repousa o argumento de suposta neutralidade desses processos no sistema educacional. Por estão razão, este trabalho recorre as teses de autores de Stake (1967), House (1973, 2000), Parlett e Hamilton (1973), Guba e Lincoln (2011), no sentido de superar a visão restrita ao âmbito funcionalista - paradigma racionalista - nos processos de monitoramento, conferindo-lhe outra perspectiva, quanto ao uso dos diagnósticos, reconhecendo sua dimensão política e ética (Silva, 2015) no tocante à tomada de decisões.

A seguir, observa-se o desenvolvimento do debate acadêmico em torno da temática monitoramento na base de dados do Scielo e Educ@ em relação ao tempo.

Gráfico 2 -

Monitoramento: publicações de artigo ao longo do tempo.

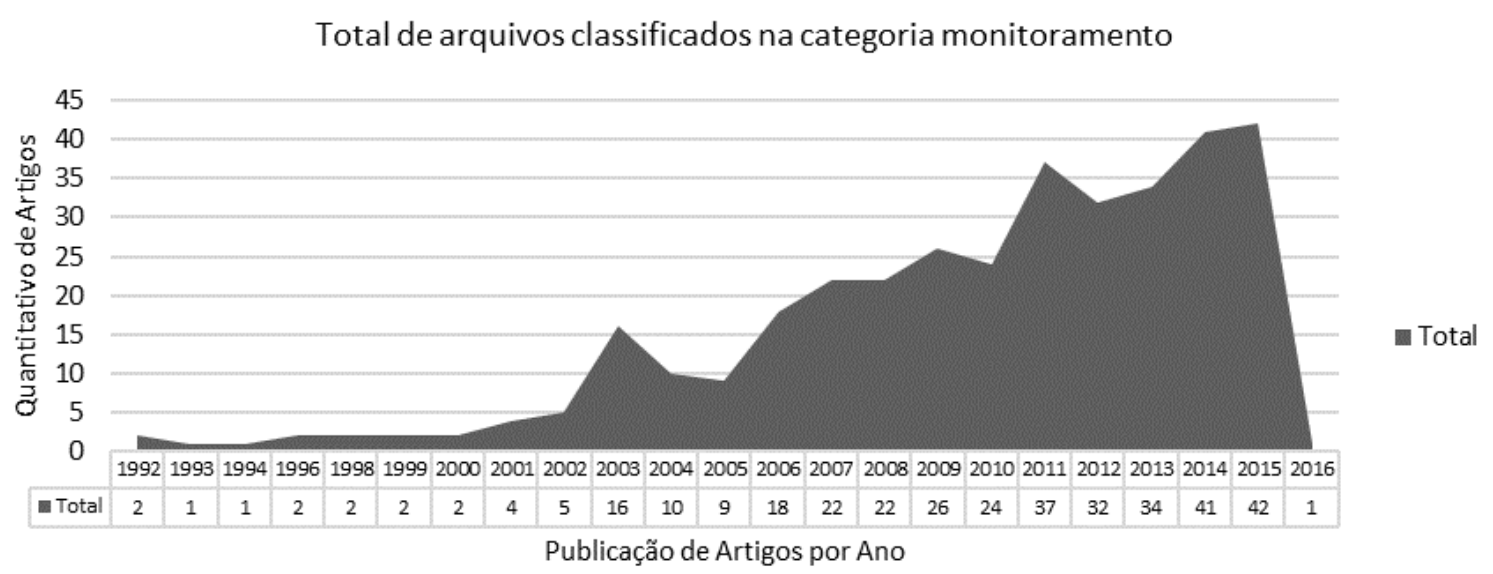

Fonte: Scielo e Educ@.

No gráfico, tomando como referência as duas bases de dados, é possível identificar o início do debate da temática em torno do monitoramento incluindo todas as áreas do conhecimento descritas no gráfico 1 , a partir da década de 1990, mais precisamente o ano de 1992, bem como perceber sua ascendente e gradual incidência até o ano de 2016. Também é interessante observar que a temática monitoramento começa a ser mais debatida a partir do ano de 2002, superando a marca de cinco trabalhos anuais. Mesmo com esse visível desenvolvimento, isso não significa reconhecer que a temática do monitoramento se desenvolveu em diversas áreas do conhecimento de maneira equilibrada, ao contrário, como aponta o gráfico 1, esse debate e discussão ocorreu de maneira distinta e assimétrica em termos quantitativos.

Essa assimetria quantitativa em relação às áreas do conhecimento e a consolidação do crescimento do número de publicações ao longo dos anos em seu conjunto levaram a necessidade de buscar levantar dados quanto ao cenário de origem desses trabalhos, se esses trabalhos tinha uma origem nacional ou internacional nessas bases de dados estudadas. 
Tabela 1 -

Monitoramento: produção acadêmica nacional e internacional na base do Scielo e Educ@.

\begin{tabular}{|c|c|c|}
\hline Base dados & País & Total \\
\hline Educ@ & BRA & 6 \\
\hline Educ@ Total & & 6 \\
\hline Scielo & BRA & 327 \\
\hline \multirow{5}{*}{} & CHI & 3 \\
\cline { 2 - 3 } & FRA & 2 \\
\cline { 2 - 3 } & HOL & 1 \\
\cline { 2 - 3 } & ITA & 3 \\
\cline { 2 - 3 } & POR & 1 \\
\cline { 2 - 3 } & URU & 4 \\
\cline { 2 - 3 } & USA & 2 \\
\cline { 2 - 3 } & ALE & 2 \\
\cline { 2 - 3 } & VEM & 2 \\
\cline { 2 - 3 } & ING & 1 \\
\cline { 2 - 3 } & SWE & 1 \\
\cline { 2 - 3 } & JAP & 1 \\
\cline { 2 - 3 } & CAN & 352 \\
\cline { 2 - 3 } & TUR & 358 \\
\hline
\end{tabular}

Fonte: Scielo e Educ@

A tabela acima apresenta quinze países, sendo o Brasil com o maior quantitativo de publicações, totalizando 327 artigos. Logo, observando os dados, reconhece-se que a temática do monitoramento, tanto no Scielo quanto no Educ@, no conjunto das áreas do conhecimento, é debatida e discutida predominantemente no âmbito nacional em detrimento do âmbito internacional. No que se refere à base do Scielo são encontrados 352 artigos tratando sobre a temática do monitoramento em diversas áreas do conhecimento. Em relação a esta mesma temática, a base do Educa@ conta com apenas seis artigos, estritamente nacionais. Como o Educ@ trata, especificamente, sobre educação, este segue as tendências das áreas de Ciências Humanas e Sociais, ou seja, pode-se inferir pelo aspecto quantitativo que a discussão sobre monitoramento no campo educacional no cenário nacional ainda não é uma temática amplamente debatida e reconhecida no bojo das duas bases de dados.

Trevisan e Bellen (2008) e Gatti (2014) oferecem pistas importantes que permitem conjecturar essa lacuna no campo da avaliação educacional, consequentemente, no campo de avaliação de políticas públicas. Os primeiros autores reportam que, na área de políticas publicas não é comum na experiência brasileira levantar e sistematizar dados para a tomada de decisões no tocante aos processos de formulação e implantação de políticas ao nível nacional e, sobretudo, local. Para a última autora, é possível reconhecer no campo da avaliação educacional brasileira lacunas indesejáveis quanto ao
Regae: Rev. Gest. Aval. Educ.
Santa Maria
v. 8
n. 17
Pub. contínua 2019
p. 1-24 
desenvolvimento de pressupostos teórico-metodológicos vigorosos que permitam a visibilidade e a viabilidade do debate em torno desta temática. Isso é corroborado por Lück (2011):

Gestão educacional envolve três funções básicas de organização do trabalho, intimamente relacionadas: planejamento, monitoramento e avaliação. Considerando-se que a educação escolar é um processo intencional e sistêmico, orientado para promover resultados propostos e característicos por elevada complexidade, evidencia-se como imprescindível que as práticas educacionais sejam criteriosamente planejadas, de modo que não sejam aleatórias, orientadas pelo senso comum, simplificadas e espontaneístas, e sim, sejam orientadas por concepções consistentes e claras e por planos de ações objetivos e organizadores de ações transformadoras, continuamente revisadas. (p. 28)

Essa proposição destacada por Lück, além de romper com a abordagem funcionalista, amparada exclusivamente na perspectiva racionalista, traz ao cenário nacional outra possibilidade ainda não explorada de modo desejável nas discussões e debates em torno da temática do monitoramento nas áreas das Ciências Humanas e das Ciências Sociais, quando aplicadas ao campo da avaliação educacional e da avaliação de políticas públicas. Nesta proposição o monitoramento fomenta com dados o processo de avaliação, em especial, a avaliação institucional, possibilitando maior alcance do autoconhecimento institucional. Dessa maneira, o monitoramento poderia vir a assumir a base dos processos de avaliação.

A seguir, foi analisada no cenário nacional, a origem por Estado das produções a respeito da temática monitoramento.

Tabela 2 -

Monitoramento: produção acadêmica nacional na base do Scielo e Educ@.

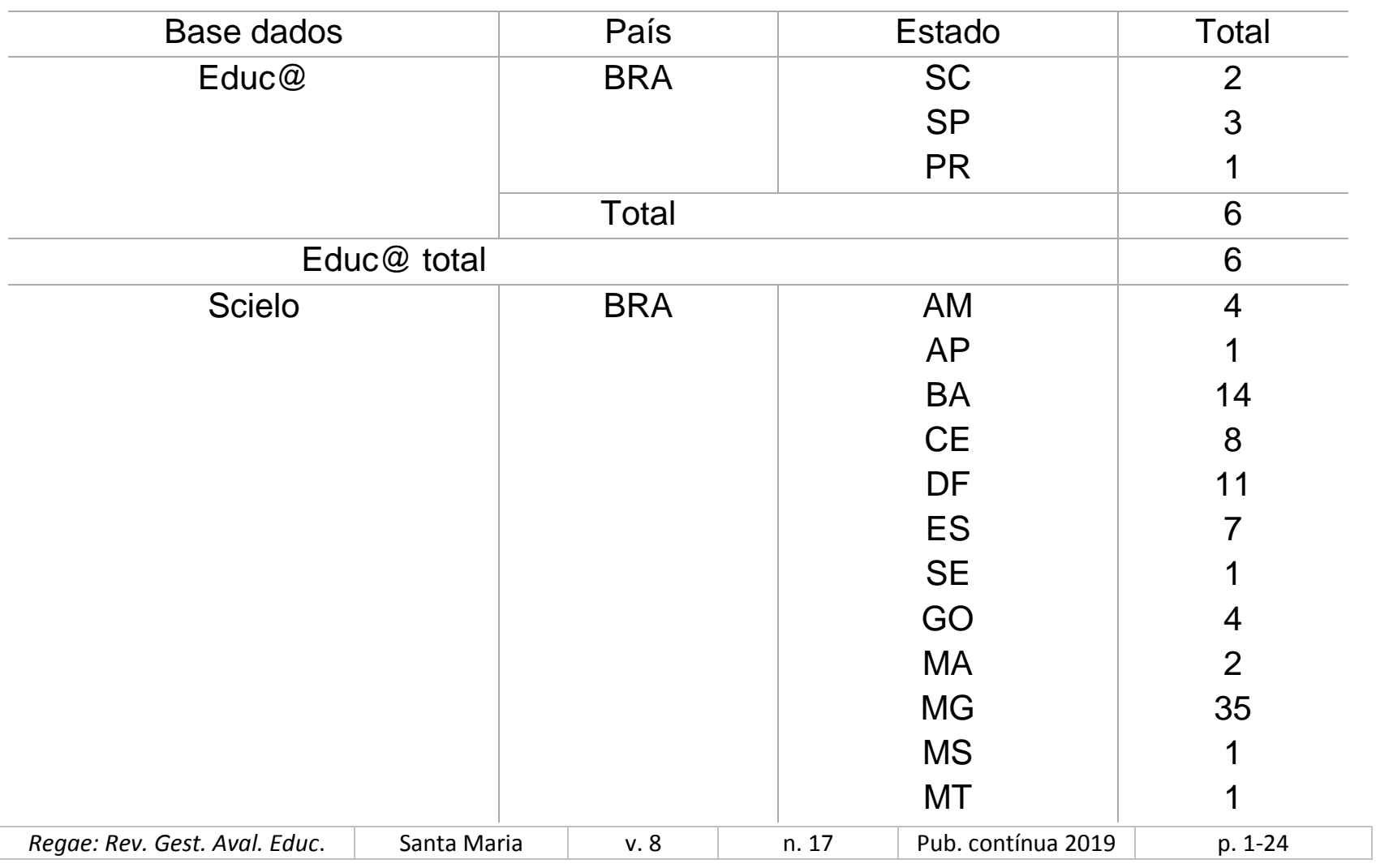




\begin{tabular}{r|c|c} 
& PA & 2 \\
& PB & 5 \\
& PE & 9 \\
& PR & 22 \\
& RJ & 36 \\
& RJ & 1 \\
& RN & 6 \\
& RS & 42 \\
& SC & 6 \\
\hline Scielo total & SP & 107 \\
\hline Total geral & & 325 \\
\hline & & 331
\end{tabular}

Fonte: Scielo e Educ@.

A origem das produções no cenário nacional sobre a temática de monitoramento concentra-se no Estado de São Paulo 110 publicações, no que se refere às duas bases de dados da pesquisa, Scielo e Educ@. Embora não se possa deixar de mencionar os Estados do Rio Grande do Sul com 45, Rio de Janeiro com 36, Minas Gerais com 35 e Paraná com 23 publicações. É importante ressaltar que essa produção foi classificada em relação a todas as áreas do conhecimento na base de dados do Scielo e na área de Ciências Humanas e Ciências Sociais na base de dados do Educ@. Na região Nordeste não aparece trabalhos da base de dados da Educ@, apenas da Scielo. Nesta última, a liderança na produção fica com o Estado da Bahia com 14 publicações.

Durante a consecução da pesquisa optou-se, para além da classificação amparada na metodologia da Scielo, buscar e verificar a temática monitoramento por meio da palavra-chave principal nas duas bases de dados. Os resultados encontrados são apresentados a seguir.

Quadro 1 -

Monitoramento: palavra-chave principal na base do Scielo e Educ@.

\begin{tabular}{|l|l|l|l|c|}
\hline $\begin{array}{c}\text { Palavra-chave } \\
\text { principal }\end{array}$ & \multicolumn{1}{|c|}{ Periódico } & $\begin{array}{c}\text { Base } \\
\text { dados }\end{array}$ & \multicolumn{1}{|c|}{ Áreas temáticas } & Total \\
\hline \multirow{3}{*}{ Monitoramento } & Ciência e Agrotecnologia & Scielo & Ciências Agrárias & 1 \\
\cline { 2 - 5 } & Acta Amazônica & Scielo & Interdisciplinar & 1 \\
\cline { 2 - 5 } & Arquivos do Instituto Biológico & Scielo & Ciências Agrárias & 1 \\
\cline { 2 - 5 } & Boletim de Ciências Geodésicas & Scielo & $\begin{array}{l}\text { Ciências Exatas e } \\
\text { da Terra }\end{array}$ & 2 \\
\hline & Bragantia & Scielo & Ciências Agrárias & 1 \\
\hline & Caderno Saúde Pública & Scielo & Interdisciplinar & 1 \\
\cline { 2 - 5 } & Ciência \& Saúde Coletiva & Scielo & $\begin{array}{l}\text { Ciências da } \\
\text { Saúde }\end{array}$ & 1 \\
\cline { 2 - 5 } & Codas & Scielo & $\begin{array}{l}\text { Ciências da } \\
\text { Saúde }\end{array}$ & 1 \\
\hline
\end{tabular}




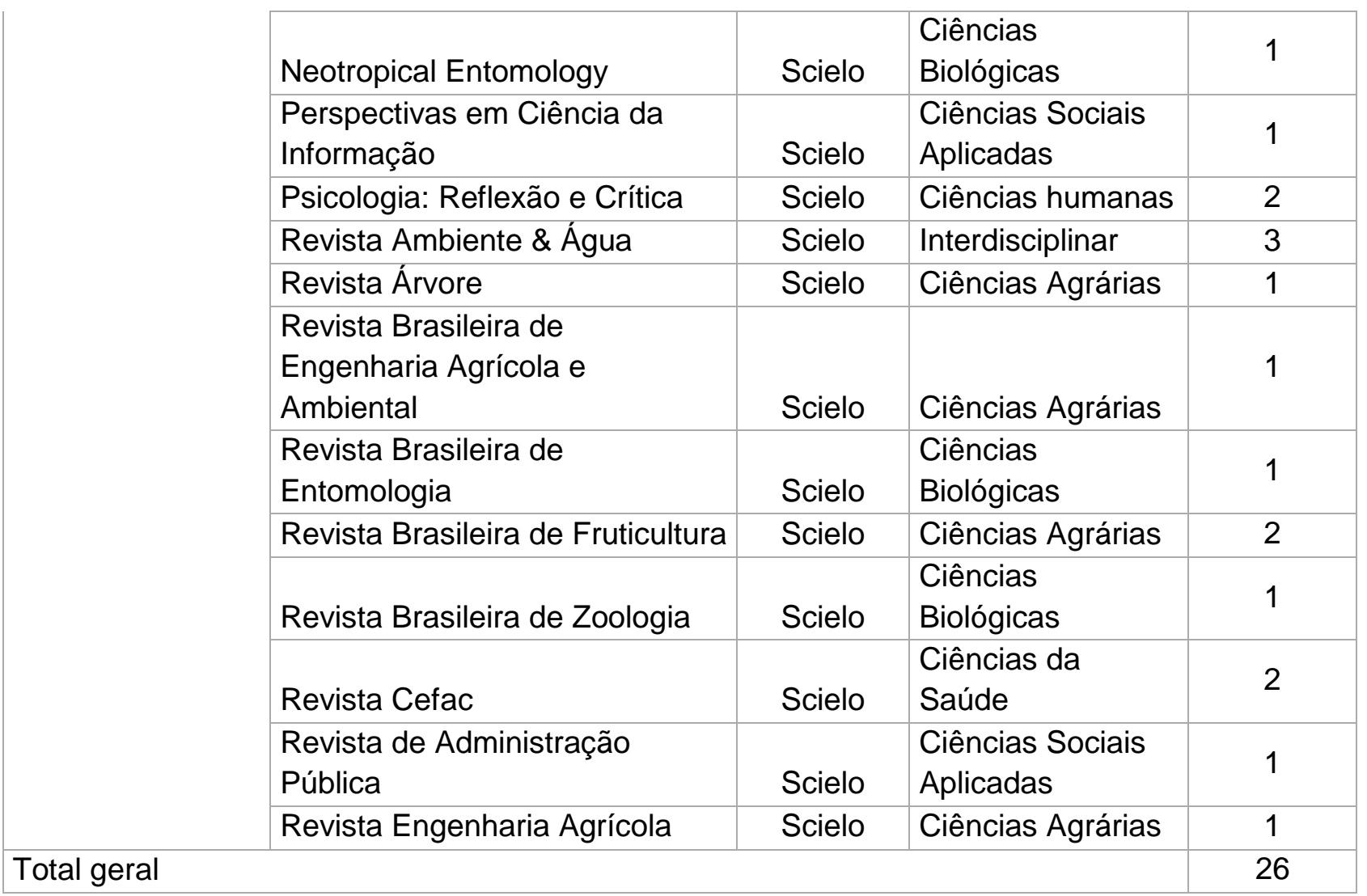

Fonte: Scielo e Educ@.

De início, observa-se que a palavra-chave monitoramento, como palavra principal, aparece apenas em uma das bases pesquisadas, a Scielo. Por esta classificação é admissível comprovar a predominância das áreas de Ciências Agrárias e Ciências da Saúde nas discussões sobre a temática monitoramento. As áreas de Ciências Humanas e Ciências Sociais, no quadro, apresentam-se em uma produção cada.

\section{A categoria monitoramento no grupo temático de ciências humanas voltados ao campo educacional no Scielo e Educ@}

Nesta seção tratar-se-á da análise das tendências e perspectiva do perfil da produção científica sobre a temática monitoramento nas áreas de Ciências Humanas voltadas ao campo educacional. Também esclarece-se que não foram encontradas publicações voltadas ao campo educacional na área de Ciências Sociais, justificando o recorte realizado. A seguir, apresenta-se um gráfico com publicações ao longo do tempo na área temática Ciências Humanas agrupados nas duas bases de dados. 
Gráfico 3 -

Monitoramento: publicações de artigo ao longo do tempo na área temática Ciências Humanas.

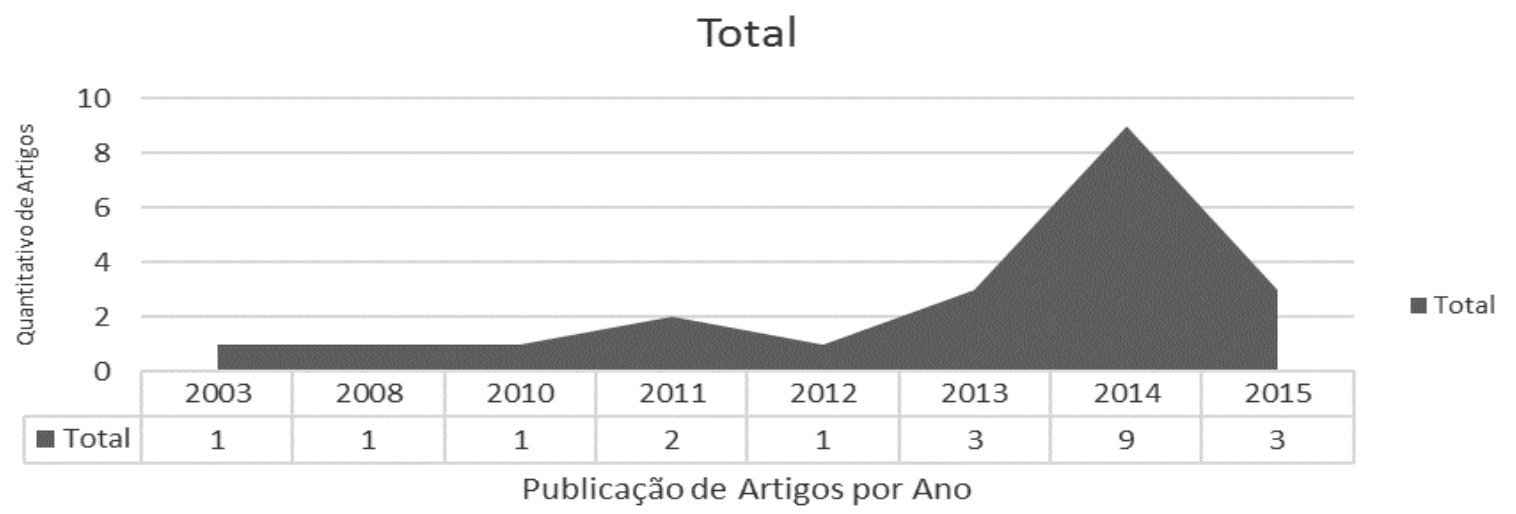

Fonte: Scielo e Educ@.

Seguindo a tendência geral, a área temática de Ciências Humanas apresenta a mesma dinâmica de ascendência das discussões a respeito da temática monitoramento. Porém, diferentemente do gráfico 2 , as discussões na base de dados pesquisada somente acontecem a partir de 2003, tomando como referência a base dados do Scielo, embora existam trabalhos na base de dados da Educ@ no mesmo grupo temático. Contudo, a distribuição destes trabalhos no tempo é recente, datando apenas do ano de 2012 e com predominância em 2014.

Utilizando a classificação por áreas do conhecimento do CNPq, a área de Educação encontra-se agrupada na área de Ciências Humanas. Já a área de Ciências Sociais agrupa a temática da avaliação de políticas públicas. Por opção, buscou-se neste trabalho dar preferência ao campo educacional como descrito pelo CNPq, excluindo-se da análise o grupo de Ciências Sociais.

Com o intuito de aprofundar as análises, as publicações encontradas nas duas bases de dados referentes à área de Ciências Humanas foram agrupadas no quadro a seguir. Antes, porém, é necessário explicitar que a temática monitoramento aparece classificada em diversos subgrupos nesta área, onde a subárea da educação, além de ser predominante, é um desses subgrupos.

Quadro 2 -

Monitoramento: produção acadêmica na Área de Humanas na base do Scielo e Educ@.

\begin{tabular}{|c|c|c|c|c|}
\hline $\begin{array}{c}\text { Áreas } \\
\text { temáticas }\end{array}$ & Referências & País & Estado & Instituição \\
\hline $\begin{array}{l}\text { Ciências } \\
\text { humanas }\end{array}$ & $\begin{array}{l}\text { ARAÚJO, A. B. Qualidade em pauta: os } \\
\text { periódicos jornalísticos e o monitoramento } \\
\text { da qualidade da educação. Roteiro, } \\
\text { Joaçaba, v. } 39 \text {, n. } 2 \text {, p. } 453-470 \text {, jul./dez. } \\
2014 \text {. }\end{array}$ & BRA & SC & USP \\
\hline Regae: Rev. G & est. Aval. Educ. & Pub. co & tínua 2019 & p. $1-24$ \\
\hline
\end{tabular}


BARRETTO, E. S. S. A avaliação na educação básica entre dois modelos. Educação \& Sociedade, ano XXII, no 75 , Agosto/2001.

BHERING, E.; ABUCHAIM, B. O. Monitoramento da educação infantil pública: possibilidades e conteúdos. Est. Aval. Educ., São Paulo, v. 25, n. 58, p. 74-99, maio/ago. 2014.

COELHO, C. L. G., CORREB, J. Desenvolvimento da Compreensão Leitora através do Monitoramento da Leitura. Psicologia: Reflexão e Crítica, 23(3), 575581. 2010.

FERNANDES, F. S. Políticas Públicas e Monitoramento na educação infantil. Est. Aval. Educ., São Paulo, v. 25, n. 58, p. 4472, maio/ago. 2014.

GARCIA,L. T. S.; SILVA FILHO, L. G.; SILVA, M. V. G. Monitoria e avaliação formativa em nível universitário: desafios e conquistas. PERSPECTIVA, Florianópolis, v. 31, n. 3, 973-1003, set./dez. 2013

JANNUZZI, P. M. Avaliação de programas sociais: conceitos e referências de quem a realiza.Est. Aval. Educ., São Paulo, v. 25, n. 58, p. 22-42, maio/ago. 2014

LISBOA, G. J. Federalismo educacional esfacelado? Um estudo de caso sobre o piso salarial. Ensaio: aval. pol. públ. Educ., Rio de Janeiro, v.23, n. 89, p. 1040-1074, out./dez. 2015.

LOBO, H. A. S., PERINOTTO, J. A. J., BOGGIANI, P. C. Monitoramento espeleoclimático do trecho turístico da caverna Santana (PETAR, SP). Mercator, Fortaleza, v. 13, n. 2, p. 227-241, mai./ago. 2014.

MADEIRA, L. M. M., GONÇALVES, D. C. O PROFAE em minas gerais: o trabalho da agência regional. Trabalho, Educação e Saúde, 1(1):153-160, 2003.

OLIVEIRA, H. M., ALBUQUERQUE, P. B. Mecanismos Explicativos das Falsas POR Memórias no Paradigma DRM.

\begin{tabular}{|l|l} 
BRA SP USP &
\end{tabular}

\begin{tabular}{l|l} 
BRA SP UFF &
\end{tabular}

\begin{tabular}{l|l} 
BRA RJ UFRJ & RJ
\end{tabular}

BRA SP FCC

BRA SP Unicamp

\begin{tabular}{l|l} 
BRA SP UFSCar &
\end{tabular}

BRA MG ITDMG

Universidade do Minho 
Psychology/Psicologia Reflexão e Crítica, 28(3), 554-564.2015.

PRÁ, J. R. Mulheres, direitos políticos, gênero e feminismo. Cadernos Pagu (43), julho-dezembro de 2014:169-196

ROMOSA, M. N. et al. Efeito de Regras Inacuradas e Monitoramento sobre Desempenhos em Programas de Reforços. Psychology/Psicologia: Reflexão e Crítica, 28(4), 813-822. 2011.

SANTOS, A. L. S., AMARO, V. E., SANTOS, M. S. T. Avaliação de metodologia de aquisição de dados para representação de feições morfológicas de praias arenosas através de modelo digital de elevação. Mercator, Fortaleza, v. 14, n. 2, p. 137-155, mai./ago. 2010

SANTOS, ET AL; Monitoramento em Promoção de Saúde: uma experiência de capacitação de adultos em um Estado do Nordeste brasileiro. Educar em Revista, Curitiba, Brasil, n. 46, p. 193-207, out./dez. 2012. Editora UFPR.

SOUZA, E. M. F., CRUZ, C. B. M., RICTER, M. O uso de geotecnologias em sistemas de transporte e organização urbana no BRASIL. Mercator, Fortaleza, v. 13, n. 1, p. 143-152, jan./abr. 2014.

ZAMPIERI, M., SCHELINI, P. W. O Uso de Medidas Intelectuais na Análise do Monitoramento Metacognitivo de Crianças.Psic.: Teor. e Pesq., Brasília, AbrJun 2013, Vol. 29 n. 2, pp. 177-183.

ZORTEA, M., JOU, G. I., SALLES, J. F. Tarefa experimental de metamemória para avaliar monitoramento e controle de memória.Psico-USF, Bragança Paulista, v. 19, n. 2, p. 329-344, maio/agosto 2014.

Fonte: Scielo e Educ@.

No quadro a temática monitoramento apresenta-se com um leque diversificado no campo da educação, abarcando problematizações a respeito da qualidade, das políticas educacionais e metodologia de ensino. Seguindo a tabela 1, nessa área, o campo da educação caracteriza-se por ser uma discussão tipicamente nacional. Para melhor compreensão de como a temática monitoramento é retratada no subcampo da educação 
na área de Ciências Humanas, associadas ao campo da avaliação educacional e da avaliação de políticas públicas, nestas duas bases de dados, apresenta-se a tabela a seguir:

Quadro 3 -

Monitoramento: área de humanas, subcampo da educação na base do Scielo e Educ@.

\begin{tabular}{|c|c|c|c|c|c|}
\hline $\begin{array}{c}\text { Áreas } \\
\text { temáticas }\end{array}$ & Referências & País & Estado & $\begin{array}{l}\text { Subárea } \\
\text { temática }\end{array}$ & $\begin{array}{c}\text { Base de } \\
\text { dados }\end{array}$ \\
\hline \multirow[t]{7}{*}{$\begin{array}{l}\text { Ciências } \\
\text { humanas }\end{array}$} & $\begin{array}{l}\text { ARAÚJO, A. B. Qualidade em pauta: } \\
\text { os periódicos jornalísticos e o } \\
\text { monitoramento da qualidade da } \\
\text { educação. Roteiro, Joaçaba, v. } 39 \text {, n. } \\
\text { 2, p. 453-470, 2014. }\end{array}$ & BRA & SC & Educação & Educ@ \\
\hline & $\begin{array}{l}\text { BHERING, E.; ABUCHAIM, B. O. } \\
\text { Monitoramento da educação infantil } \\
\text { pública: possibilidades e conteúdos. } \\
\text { Est. Aval. Educ., São Paulo, v. } 25 \text {, n. } \\
\text { 58, p. 74-99, 2014. }\end{array}$ & BRA & SP & Educação & Educ@ \\
\hline & $\begin{array}{l}\text { FERNANDES, F. S. Políticas públicas } \\
\text { e monitoramento na educação infantil. } \\
\text { Est. Aval. Educ., São Paulo, v. } 25 \text {, n. } \\
58, \text { p. } 44-72,2014 \text {. }\end{array}$ & BRA & SP & Educação & Educ@ \\
\hline & 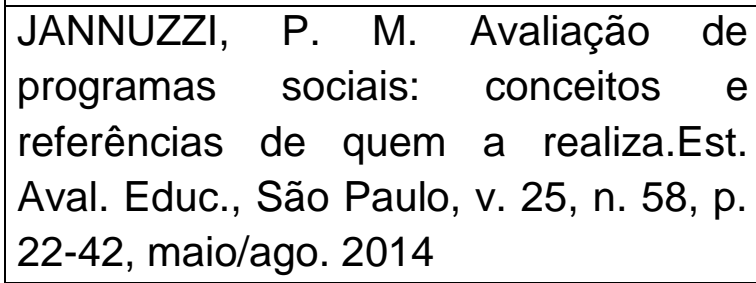 & BRA & SP & Educação & Educ@ \\
\hline & $\begin{array}{l}\text { SANTOS, et al; Monitoramento em } \\
\text { Promoção de Saúde: uma experiência } \\
\text { de capacitação de adultos em um } \\
\text { Estado do Nordeste brasileiro.Educar } \\
\text { em Revista, Curitiba, Brasil, n. 46, p. } \\
\text { 193-207, 2012. }\end{array}$ & BRA & PR & Educação & Educ@ \\
\hline & $\begin{array}{l}\text { GARCIA,L. T. S.; SILVA FILHO, L. G.; } \\
\text { SILVA, M. V. G. Monitoria e avaliação } \\
\text { formativa em rível } \\
\text { universitário: desafios e conquistas. } \\
\text { Perspectiva, Florianópolis, v. } 31 \text {, n. 3, } \\
\text { 973-1003, set./dez. } 2013\end{array}$ & BRA & SC & Educação & Educ@ \\
\hline & $\begin{array}{l}\text { BARRETTO, E. S. S. A avaliação na } \\
\text { educação básica entre dois modelos. } \\
\text { Educação \& Sociedade, ano XXII, no } \\
75,2001 .\end{array}$ & BRA & SP & Educação & Scielo \\
\hline
\end{tabular}




\begin{tabular}{|c|c|c|c|c|}
\hline $\begin{array}{l}\text { LISBOA, G. J. Federalismo } \\
\text { educacional esfacelado? Um estudo de } \\
\text { caso sobre o piso salarial. Ensaio: } \\
\text { aval. pol. públ. Educ., Rio de Janeiro, } \\
\text { v.23, n. 89, p. 1040-1074, } 2015 .\end{array}$ & BRA & BA & Educação & Scielo \\
\hline $\begin{array}{l}\text { MADEIRA, L. M. M., GONÇALVES, D. } \\
\text { C. O PROFAE EM MINAS GERAIS: O }\end{array}$ & & & & \\
\hline $\begin{array}{l}\text { TRABALHO DA AGÊNCIA } \\
\text { REGIONAL. Trabalho, Educação e } \\
\text { Saúde, 1(1):153-160, } 2003 .\end{array}$ & BRA & MG & Educação & Scielo \\
\hline $\begin{array}{l}\text { ROMOSA, M. N. et al. Efeito de } \\
\text { Regras Inacuradas e Monitoramento } \\
\text { sobre Desempenhos em Programas de } \\
\text { Reforços.Psychology/Psicologia: } \\
\text { Reflexão e Crítica, 28(4), 813-822. } \\
2011 .\end{array}$ & BRA & PR & Educação & Scielo \\
\hline $\begin{array}{l}\text { ZAMPIERI, M., SCHELINI, P. W. O } \\
\text { Uso de Medidas Intelectuais na Análise } \\
\text { do Monitoramento Metacognitivo de } \\
\text { Crianças. Psic.: Teor. e Pesq., Brasília, } \\
\text { Abr-Jun 2013, Vol. } 29 \text { n. 2, p. 177-183. }\end{array}$ & BRA & SP & Educação & Scielo \\
\hline $\begin{array}{l}\text { ZORTEA, M., JOU, G. I., SALLES, J. } \\
\text { F. Tarefa experimental de } \\
\text { metamemória para avaliar } \\
\text { monitoramento e controle de memória. } \\
\text { Psico-USF, Bragança Paulista, v. } 19 \text {, } \\
\text { n. } 2 \text {, p. } 329-344,2014 .\end{array}$ & BRA & RS & Educação & Scielo \\
\hline
\end{tabular}

Fonte: Scielo e Educ@

Com o mapeamento dos trabalhos na temática monitoramento associados ao campo da avaliação educacional e da avaliação de políticas públicas foi aceitável encontrar algumas características relevantes: a) a discussão sobre monitoramento é uma discussão recente; b) as publicações associando a temática monitoramento ao campo da avaliação educacional e avaliação de políticas públicas foram encontradas com predominância na base de dados da Educ@. Não obstante, foi encontra um trabalho na base do Scielo. Porém, é necessário destacar que este trabalho no Scielo não traz o monitoramento como uma estratégia no desenvolvimento das políticas públicas, apenas como um artifício para analisar o desempenho do piso salarial dos docentes; c) as discussões sobre monitoramento na base do Scielo tendem a ser amparadas em discussões de cunho metodológico voltados ao ensino-aprendizagem, ou tratar a temática em um aspecto mais geral. Então, voltando ao quadro, foi possível classificar três trabalhos com as características propostas pelo objetivo geral, como descrito a seguir: 
Quadro 4 -

Trabalhos na área de Ciências Humanas com a temática monitoramento voltados ao campo da avaliação educacional e avaliação de políticas públicas.

\begin{tabular}{|l|l|l|l|l|}
\hline $\begin{array}{l}\text { BHERING, E.; ABUCHAIM, B. O. } \\
\text { Monitoramento da educação infantil pública: } \\
\text { possibilidades e conteúdos. Est. Aval. Educ., }\end{array}$ & BRA & SP & Educação & Educ@ \\
$\begin{array}{l}\text { São Paulo, v. 25, n. 58, p. 74-99, maio/ago. } \\
\text { 2014. }\end{array}$ & & & & \\
\hline $\begin{array}{l}\text { FERNANDES, F. S.; Políticas Públicas e } \\
\text { Monitoramento na educação infantil. Est. Aval. } \\
\text { Educ., São Paulo, v. 25, n. 58, p. 44-72, } \\
\text { maio/ago. 2014. }\end{array}$ & BRA & SP & Educação & Educ@ \\
\hline $\begin{array}{l}\text { JANNUZZI, P. M. Avaliação de programas } \\
\text { sociais: conceitos e referências de quem a } \\
\text { realiza.Est. Aval. Educ., São Paulo, v. 25, n. 58, } \\
\text { p. 22-42, maio/ago. 2014 }\end{array}$ & BRA & SP & Educação & Educ@ \\
\hline $\begin{array}{l}\text { BARRETTO, E. S. S. A avaliação na educação } \\
\text { básica entre dois modelos. Educação \& } \\
\text { Sociedade, ano XXII, n. 75, 2001. }\end{array}$ & BRA & SP & Educação & Scielo \\
\hline
\end{tabular}

Fonte: Scielo e Educ@.

Na pesquisa realizada foram encontrados apenas quatro trabalhos sobre a temática monitoramento envolvendo os campos da avaliação educacional e de avaliação de políticas publicas nas duas bases de dados (Scielo e Educ@). Dos quatro, dois abordam as políticas da educação infantil, um a avaliação de programas sociais e um a avaliação na educação básica. Então, das quatro publicações, três tratam da temática sobre o prisma do campo da avaliação de políticas publicas, embora as duas primeiras publicações aproximem mais este campo do campo da avaliação educacional. Já, o último trabalho faz uma discussão sobre monitoramento voltando-se essencialmente para o campo da avaliação educacional.

Também, pesquisou-se o banco de dados remanescente: Portal de Periódicos da Capes. Depois disso, efetivou-se a análise de cunho empírico e analítico a respeito das temáticas anunciadas e associadas ao contexto das políticas educacionais, a partir da análise de exemplos que estimulassem a compreensão, para verificar quais são as permanências, avanços e tendências da pesquisa e da produção acadêmica no campo empírico e teórico conceitual a respeito do monitoramento. 
Gráfico 4 -

Monitoramento: publicações de trabalhos - teses, dissertações e artigos - ao longo do tempo na base Periódicos Capes.

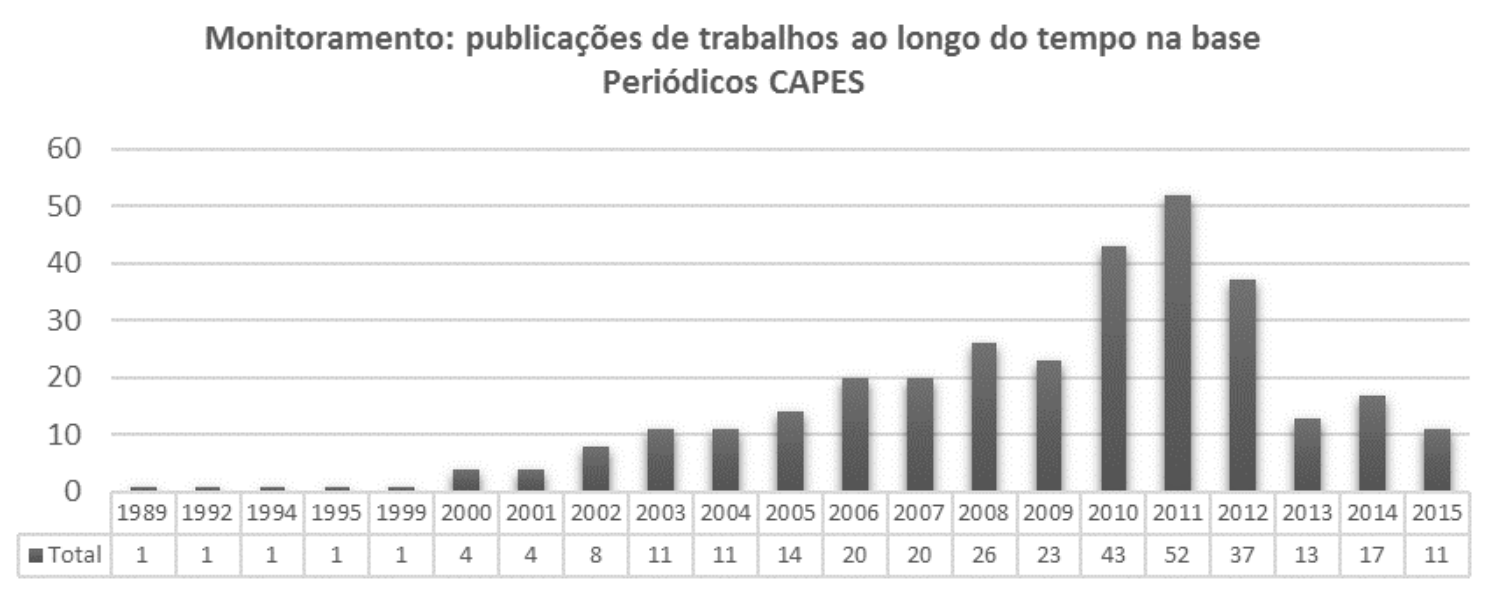

Fonte: Capes.

No gráfico, tendo como referência a base de dados o Periódico Capes, a produção cientifica inicia-se a partir do ano de 1989 até o ano de 2015. É visível o crescimento da produção no ano de 2000, apresentando quatro trabalhos. Houve um maior crescimento nas publicações no ano de 2011, com 52 artigos publicados. A partir do ano de 2012 observa-se um decréscimo da produção.

Gráfico 5 -

Monitoramento: publicações por tipo de trabalho ao longo do tempo na base Periódicos Capes.

Monitoramento: publicações por tipo de trabalho ao longo do tempo na base Periódicos CAPES

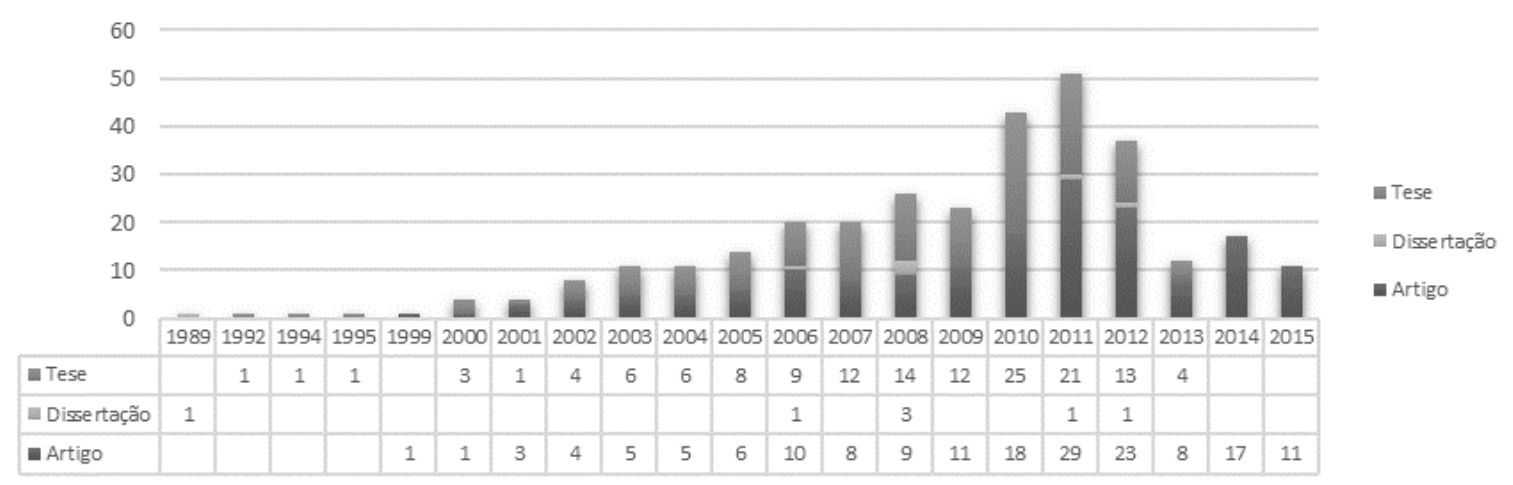

Fonte: Capes.

No gráfico 5 demostram-se os tipos de publicações de trabalhos de acordo com o tempo, apresentando-se os seguintes tipos de publicações: tese, dissertações e artigos. Evidencia-se a predominância de publicações do tipo de artigo, em segundo tese e por último dissertações. Em relação ao tipo de publicação artigo foram publicados 196, no tipo tese foram publicados 143 e em dissertação foram publicados sete. 
De acordo com o gráfico, o ano de 2010 apresentou o maior quantitativo de publicações do tipo tese. No ano de 2011 a maior quantidade de publicações do tipo artigo. No que se refere ao ano de 2008 o maior quantitativo de publicações do tipo dissertação. Nos últimos três anos não ocorreu publicações do tipo dissertação. Nos dois últimos não apresentou publicações do tipo eese. Logo, a publicação do tipo artigo ocorreu em todos os anos a partir de 1999. Nos quatro primeiros anos, de acordo com a análise, não apresentou publicação do tipo artigo, visto que as publicações foram predominantemente do tipo tese.

Gráfico 6 -

Monitoramento: publicações por áreas do conhecimento na base de dados do Periódicos Capes.

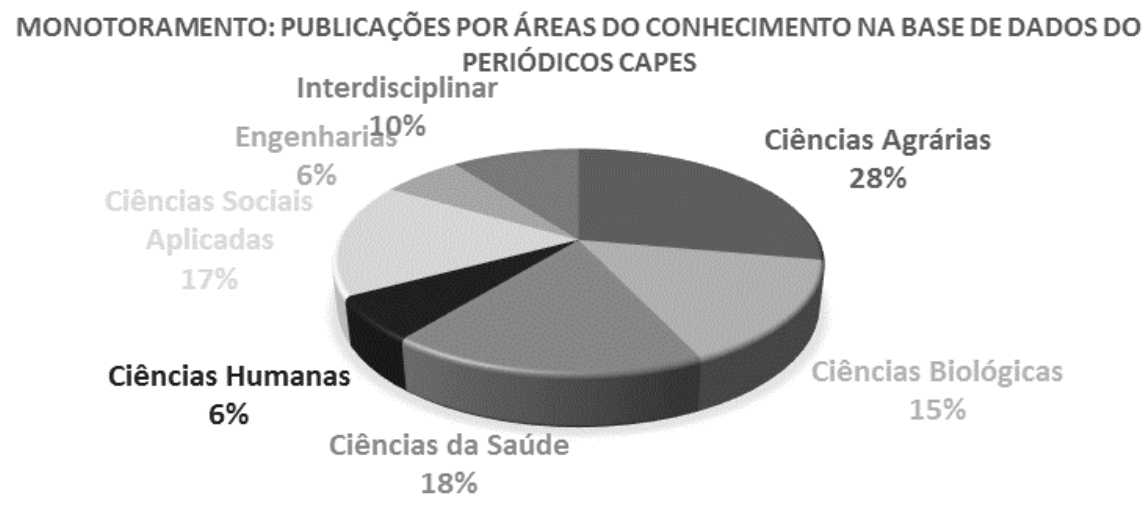

Fonte: Capes.

No gráfico 6 observa-se o quantitativo por área dos artigos encontrados na base de dados Periódicos Capes disponibilizado no site. Foram encontradas as seguintes áreas: Ciências Agrárias, Ciências Biológicas, Ciências da Saúde, Ciências Humanas, Ciências sociais Aplicadas, Engenharias e Interdisciplinar. A área Ciências Agrárias abrange 28\% de publicações, na área de Ciências Biológicas foram encontrados 15\%, na área de Ciências da Saúde foram encontrados 18\%, na área de Ciências Humanas $6 \%$, na área de Ciências Sociais Aplicadas 17\%, na área de Engenharias 6\% e na área Interdisciplinar 10\%. Tendência semelhante a encontrada nas bases de dados do Scielo e Educ@. 
Gráfico 7 -

Palavra-chave principal monitoramento: áreas do conhecimento na base Periódicos Capes.

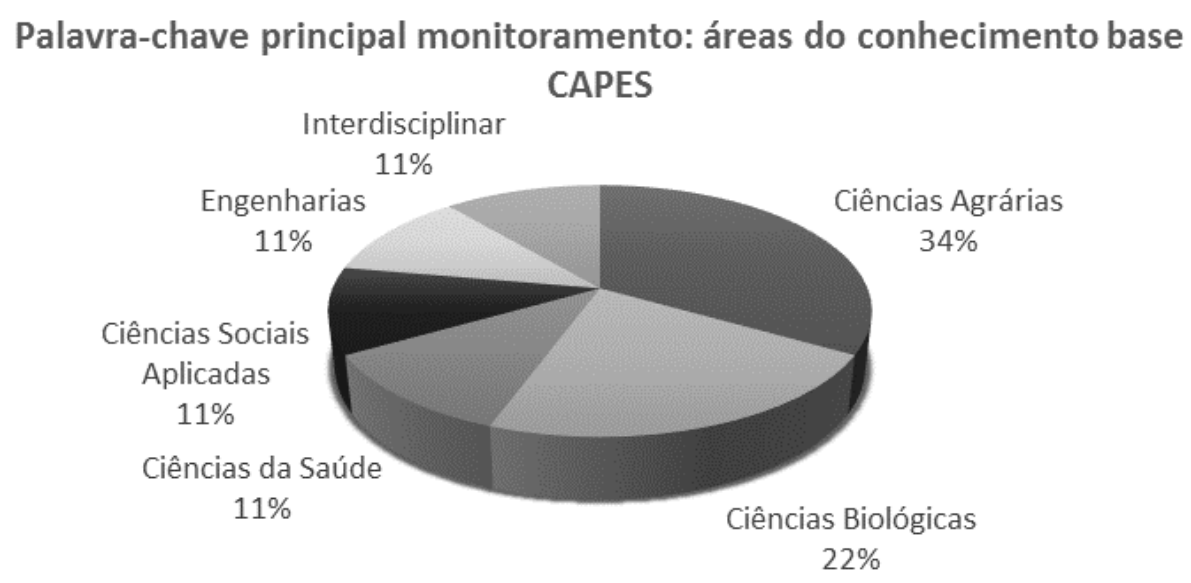

Fonte: Capes.

O gráfico 7 aponta os artigos com as áreas de conhecimento que apresenta a palavra-chave principal: monitoramento. De acordo com o gráfico as áreas são: Ciências Agrárias, Ciências Biológicas, Ciências da Saúde, Ciências Sociais Aplicadas, Engenharias e Interdisciplinar. A maior quantidade artigos é da área de Ciências Agrárias: $34 \%$ dos trabalhos. Em segundo, a área de Ciências Biológica com $22 \%$. As áreas Interdisciplinar, Engenharias, Ciências Sociais Aplicadas e Ciências da Saúde abrengem $11 \%$. É importante destacar que a categoria temática monitoramento, nesta base de dados, não destaca nenhum artigo na área de ciência humanas, quando classificada pela palavra-chave principal, indicando ser uma discussão secundária nesta área do conhecimento. Quando classificada pelo método geral da Capes, a categoria temática monitoramento aparece como indicado no quadro a seguir:

Quadro 5 -

Categoria temática monitoramento na área de ciências humanas: periódicos, artigos, país e ano na base periódicos Capes.

\begin{tabular}{|l|l|c|c|}
\hline \multicolumn{1}{|c|}{ Periódico } & \multicolumn{1}{|c|}{ Artigos } & País & Ano \\
\hline Educação \& sociedade & $\begin{array}{l}\text { BARRETTO, E. S. S. A AVALIAÇÃO NA } \\
\text { EDUCAÇÃO BÁSICA ENTRE DOIS MODELO. } \\
\text { Educação \& sociedade [0101-7330] yr:2001 vol:22 } \\
\text { iss:75 pg:48 -66 }\end{array}$ & Brasil & 2001 \\
\hline Psicol. USP & $\begin{array}{l}\text { CARVALHO, A. M. A. Monitoramento e avaliação } \\
\text { da pós-graduação: algumas reflexões sobre } \\
\text { requisitos e critérios. Psicol. USP v. 12 n. 1 São } \\
\text { Paulo, 2001. }\end{array}$ & Brasil & 2001 \\
\hline $\begin{array}{l}\text { Psicologia: Reflexão e entica } \\
\text { Crítica }\end{array}$ & $\begin{array}{l}\text { COELHO, C. L. G. CORREA, J. Desenvolvimento } \\
\text { da compreensão leitora através do monitoramento } \\
\text { da leitura. Psicologia: reflexão e crítica [0102-7972] } \\
\text { yr:2010 v. 23 iss:3 p:575 -581 }\end{array}$ & Brasil & 2010 \\
\hline
\end{tabular}

Fonte: Portal de Periódicos Capes.

\begin{tabular}{l|l|l|l|l|r|} 
Regae: Rev. Gest. Aval. Educ. & Santa Maria & v. 8 & n. 17 & Pub. contínua 2019 & p. 1-24
\end{tabular} 
De acordo, com o quadro cinco foram encontrados três artigos na área de Ciências Humana, sobre a temática monitoramento. Na classificação, na área de Ciências Humanas, foram encontrados os seguintes periódicos: Educação \& Sociedade, Psicol. USP e Psicologia: Reflexão e Crítica. Cada periódico apresenta um artigo. Dos três, um aborda o monitoramento na avaliação educacional articulado ao campo das políticas educacionais e dois tratam a temática do monitoramento no campo da Psicologia, referenciando-se a tradição psicométrica no campo da avaliação educacional e, também, articulado a políticas educacionais. O recorte temporal é antigo, portanto distanciando-se do tempo presente.

Embora antigo, o artigo da Revista Educação \& Sociedade busca aprofundar a análise de alguns modelos de avaliação na educação básica que persistem até os dias atuais. Trata-se de um levantamento do estado da arte a respeito do tema no Brasil nos anos de 1990. Constata dois modelos de avaliação no país neste nível de ensino, um de base emancipatória e o outro de base reguladora aportado nos interesses do Estado em legitimar sua governança no sistema educacional. Neste artigo o conceito de monitoramento emerge no seu sentido tradicional - concepção racionalista:

No monitoramento dos sistemas de ensino básico, a ênfase tem recaído, via de regra, sobre o uso da informação gerada pela avaliação como subsídio aos próprios aparatos gestores das redes de ensino, prestando-se de preferência a orientar ações do Estado no sentido de suprir necessidades detectadas. (Barretto, 2001, p. 60)

O trabalho da Revista Psicologia da USP discute algumas questões que emergiram como relevantes para a reflexão sobre o monitoramento e avaliação de cursos de pósgraduação em Psicologia Experimental. Traz uma concepção de monitoramento distinta da perspectiva tradicional, voltando os dados do monitoramento para a comunidade do curso - discentes, professores e coordenador -, como estratégia de autoavaliação, uma concepção semelhante a defendida pelo projeto pesquisa, ao qual está vinculado este plano de trabalho. A tese defendida sugere a necessidade de auto-monitoramento do curso como instrumento para a validação ou o questionamento de avaliações externas.

Por fim, o trabalho da Revista Psicologia: reflexão e crítica que aborda em sua perspectiva clássica, diagnóstico de causa e efeito aplicado ao processo de ensino e aprendizagem. Este trabalho não articula o monitoramento ao campo da política educacional.

Então, nos trabalhos analisados verifica-se que apenas em dois o monitoramento aparece no campo da avaliação educacional associado às políticas educacionais. Nenhum dos trabalhos associou a temática do monitoramento à avaliação de políticas públicas e tecnologia de informação.

\section{Considerações finais}

A temática monitoramento, como apresentada, não é uma temática nova, se considerar o cenário da literatura acadêmica internacional. Todavia, a partir da análise das três bases de dados - Scielo, Educ@ e Portal de Periódico da Capes -, a discussão no campo educacional envolvendo dois subcampos do conhecimento interdependentes - 
avaliação educacional e avaliação de políticas públicas - é uma discussão recente. Porém, mesmo sendo recente apresenta o tensionamento paradigmático das discussões realizadas no cenário internacional.

Com o desenvolvimento do trabalho, foi possível conhecer quais as principais características deste tensionamento no cenário nacional, identificando permanências, avanços, limitações e lacunas na problematização desta temática, assim como reconhecer que há um longo e sinuoso caminho a percorrer no uso do monitoramento no campo educacional, pois tal uso significa romper com as abordagens clássicas do monitoramento para se buscar abordagens alternativas com o intuito de si aproximar dos aspectos mais qualitativos inerentes às políticas educacionais e a gestão das instituições de educação.

\section{Referências}

AZEVEDO, Janete Maria Lins. A educação como política pública. Campinas: Autores Associados, 2004.

BELLONI, Isaura; MAGALHÃES, Heitor; SOUSA, Luzia Costa. Metodologia de avaliação em políticas públicas. São Paulo: Cortez, 2007.

COHEN, Ernesto; FRANCO, Rolando. Avaliação de projetos sociais. Petrópolis: Vozes, 2008.

DUPRIEZ, Vincent; MAROY, Christian. La régulation dans les systems scolaires. Revue Française de Pédagogie, v 130, n. 1, 2000, p. 73-87. Disponível em https://www.persee.fr/doc/rfp_0556-7807_2000_num_130_1_1054. Acesso em 5 dez. 2014.

GATTI, Bernadete Angelina. Avaliação: contextos, histórias e perspectivas. Olh@res, Guarulhos, v. 2, n. 1, 2014, p. 8-26.

GOMES, Alfredo Macedo. Políticas públicas e gestão da educação. Campinas: Mercado de Letras, 2011.

GUBA, Egon G; LINCOLN, Yvonna Sessions. Avaliação de quarta geração. Campinas: Unicamp, 2011.

HOUSE, Ernest Robert. Evaluación, ética y poder. Madrid: Morata, 2000.

HOUSE, Ernest Robert. School evaluation: the politics and process. Berkeley: McCutchan, 1973.

LANDSHEERE, Gilbert. A natureza da pilotagem. In: LANDSHEERE, G. A pilotagem dos sistemas de educação. Lisboa: Asa, 1997.

LÜCK, Heloisa. Perspectivas da avaliação institucional da escola. Petrópolis: Vozes, 2012.

MAINARDES, Jefferson.- Abordagem do ciclo de políticas: uma contribuição para a análise de políticas educacionais. Educação e Sociedade, Campinas, v. 27, n. 94, 2006, p. 47-69.

MARCONI, Marina Andrade; LAKATOS, Eva Maria. Fundamentos de metodologia científica. São Paulo: Atlas, 2010.

PARLETT, Malcolm; HAMILTON, David. Evaluation as ilumination: a new approach to the study of innovatory programmes. Edinburgh: Centre for Research in the Educational Sciences, University of Edinburgh, 1972. 
RUSSELL, Michael; AIRASIAN, Peter. Avaliação em sala de aula: conceitos e aplicações. Porto Alegre: AMGH, 2014.

SILVA, Assis. Leão. Avaliação institucional no Sistema Nacional de Avaliação da Educação Superior (Sinaes). Recife: UFPE, 2015. 372f. Tese (doutorado em Educação). Centro de Educação, Universidade Federal de Pernambuco.

STAKE, Robert. Pesquisa qualitativa: estudando como as coisas funcionam. Porto Alegre: Penso, 2011.

STAKE, Robert. The countenance of educational evaluation. Teachers College Record, 68, n. 7,1967 , p. 523-540.

Vilma de Albuquerque Santos é licenciada em Química pelo Instituto Federal de Educação, Ciência e Tecnologia de Pernambuco, campus Vitória, e estudante do curso mestrado em Educação Ciências e Matemática pela Universidade Federal de Pernambuco.

Endereço: Propriedade Terra Preta, s/n, zona rural - 55602-970 - Vitória de Santo Antão - PE - Brasil.

Orcid: https://orcid.org/0000-0002-9717-0342.

E-mail: vilmaalbuquerque19@gmail.com.

Assis Leão da Silva é licenciado em História, mestre e doutor em Educação pela Universidade Federal de Pernambuco.

Endereço: Propriedade Terra Preta, s/n, zona rural - 55602-970 - Vitória de Santo Antão - PE - Brasil.

Orcid: https://orcid.org/0000-0002-5926-652X.

E-mail: assisleao33@gmail.com.

Cristiano Dornelas de Andrade é técnico em assuntos educacionais no Centro Acadêmico de Vitória da Universidade Federal de Pernambuco. Professor, coordenador do curso de Pedagogia e presidente da CPA da Faculdade Escritor Osman da Costa Lins.

Endereço: Propriedade Terra Preta, s/n, zona rural - 55602-970 - Vitória de Santo Antão - PE - Brasil.

Orcid: https://orcid.org/0000-0002-5310-9072.

E-mail: cristianodornelas@hotmail.com

Wilma dos Santos Ferreira tem graduação em Pedagogia pela Faculdade de Filosofia Ciências e Letras de Caruaru e integra os grupos de pesquisas da Universidade Federal de Pernambuco.

Endereço: Propriedade Terra Preta, s/n, zona rural - 55602-970 - Vitória de Santo Antão - PE - Brasil

Orcid: https://orcid.org/0000-0002-2477-3943.

E-mail: wilmadsferreira@gmail.com.

Recebido em 6 de janeiro de 2019.

Aceito em 2 de março de 2019.

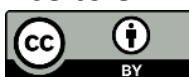

